\title{
Asexuality cured: the relations and differences between sexual and asexual Apoanagyrus diversicornis
}

\author{
JANINE W.A.M. PIJLS*, HANS J. VAN STEENBERGEN \& JACQUES J. M. VAN \\ ALPHEN \\ Leiden University, Institute of Evolutionary and Ecological Sciences, Kaiserstraat 63, 2311 GP Leiden, \\ The Netherlands
}

\begin{abstract}
We investigated whether asexual (thelytokous) Apoanagyrus diversicornis and sexual (arrhenotokous) $A$. diversicornis (Hymenoptera: Encyrtidae) belong to the same biological species. The strains are allopatric and there are no morphological differences. The sexual $A$. diversicornis strain originates from south-western Brazil. It was introduced into Africa for the biological control of the cassava mealybug Phenacoccus manihoti. The asexual strain parasitizes $P$. herreni in Colombia. Feeding antibiotics to asexual $A$. diversicornis or rearing parasitized hosts at 33 instead of $25^{\circ} \mathrm{C}$ led to male offspring production. These males could be crossed with virgin females of the sexual strain, leading to fertile female (i.e. hybrid) offspring. There were no indications of hybrid breakdown. Thus, asexuality in $A$. diversicomis is caused by microorganisms, can be cured, and the two strains belong to the same biological species. The microorganisms associated with thelytoky in A. diversicornis belong to the genus Wolbachia. There were differences between $A$. diversicornis strains and between host species in survival probability from egg to adult. In addition, some mortality was associated with the feeding of tetracycline and with the production of males, but not with rifampicin, sulphadiazine (which was not effective), or a temperature increase from 25 to $33^{\circ} \mathrm{C}$. Survival of hybrids was intermediate between the survival probabilities of the parental strains. Male behaviour and function were not different between the strains, but female behaviour clearly was. Females of the thelytokous strain were less often inseminated by males of either strain than were arrhenotokous females. This suggests a difference in the rate of decay between expressed traits (female sexual behaviour, which is possibly selected against) and traits that are not expressed (male sexual behaviour and function).
\end{abstract}

Keywords: microbial infection, parthenogenesis, sexual behaviour decay, taxonomy, thelytoky, Wolbachia.

\section{Introduction}

Thelytoky is the production of only female offspring in hymenopterous parasitoids by way of parthenogenesis. Males may occasionally be observed in thelytokous populations, sometimes induced by high temperatures (over $30^{\circ} \mathrm{C}$ ) (e.g. Gordh \& Lacey (1976); Laraichi (1978)). The 'normal' mode of reproduction in the Hymenoptera is arrhenotoky. Males, arising from unfertilized eggs, are haploid, whereas females are diploid and arise from fertilized eggs. The terms 'asexual', 'parthenogenetic' and 'uniparental' are used synonymously with 'thelyto-

\footnotetext{
*Correspondence
}

kous' in the Hymenopteran literature, and 'sexual' and 'biparental' are synonymous with 'arrhenotokous'. Arrhenotokous and thelytokous females can be distinguished by the sex of offspring of virgin females: male in arrhenotokous, female in thelytokous strains.

Recently, thelytoky has been recognized to be frequently associated with infection of the parasitoid by rickettsias of the genus Wolbachia. The Wolbachia are cytoplasmically inherited through eggs, but not through sperm. Male hosts therefore constitute a dead end: Wolbachia cannot reproduce beyond the life of a male host. Wolbachia advance their own transmission in a number of ways by causing their host to produce more female offspring than unin- 
fected individuals. Apart from cytoplasmic incompatibility (Breeuwer et al., 1992; O’Neill et al., 1992) or a change of genotypic males into phenotypic females (Rousset et al., 1992) (which will not be discussed here), Wolbachia can cause complete thelytoky in parasitoid wasps (Stouthamer et al., 1993; Werren et al., 1995). Such infected wasps produce daughters from unfertilized eggs. They can be 'cured' (i.e. rendered arrhenotokous) by treatment with antibiotics or high temperatures, which kills the microorganisms (Stouthamer et al., 1990a) and causes the females to produce male offspring. There are also forms of asexuality, however, which are not associated with microorganisms (Stouthamer et al., 1990b).

Some parasitoid species consist of both thelytokous and arrhenotokous individuals. Examples are Apoanagyrus diversicornis (Howard) [previously Epidinocarsis diversicornis (Howard) (Noyes \& Hayat, 1994)], where (as far as we know) arrhenotokous and thelytokous populations are geographically separated (Pijls \& van Alphen, 1996), and several Trichogramma spp., in which arrhenotokous and thelytokous individuals may co-occur in the same locality (Stouthamer et al., 1990b). The thelytokous Trichogramma strains referred to are infected with Wolbachia. In other species, infection with microorganisms has gone to fixation and only females exist. Examples of the latter are Encarsia formosa (Zchori-Fein et al., 1992), Leptopilina australis and L. clavipes (I.E.M. Eijs, pers. comm.).

Apoanagyrus diversicornis (Howard) (Hymenoptera: Encyrtidae) is a solitary endoparasitoid of mealybugs. It is native of South America. In Colombia, a thelytokous strain is known from the mealybug Phenacoccus herreni Cox and Williams (Homoptera: Pseudococcidae) (Van Driesche et al., 1987). A strain with an arrhenotokous mode of reproduction was found on the closely related mealybug $P$. manihoti Matile-Ferrero in Paraguay and south-western Brazil (Löhr et al., 1990). Over the last decade, attempts have been made to introduce the southwest Brazilian strain into Africa in addition to the congeneric sympatric endoparasitoid $A$. lopezi $\mathrm{De}$ Santis, for the biological control of the cassava mealybug $P$. manihoti (Herren \& Neuenschwander, 1991). The $A$. diversicornis strains will henceforth be abbreviated TD for the (thelytokous) strain from Colombia and $\mathrm{AD}$ for the (arrhenotokous) strain from southwestern Brazil. There are no morphological differences between $\mathrm{AD}$ and TD (J.S. Noyes, pers. comm.).

The interest in this system arose partly from applied research, where we wanted to know whether the strains are indeed the same species (Pijls \& van Alphen, 1996). The systematics of thelytokous populations have been problematic because it was not possible to use crosses to determine the relationship between populations. Naming them separately solely because of their mode of reproduction did not seem appropriate (J.S. Noyes, pers. comm.). The occasional occurrence of males in our culture of the thelytokous strain during spells of hot weather indicated that the asexuality might be curable, because it might be caused by a microbial infection. If we could obtain males by curing TD females, we would be able to test if TD and $\mathrm{AD}$ are the same biological species.

We investigated how thelytoky in $A$. diversicornis is caused, and whether TD and $\mathrm{AD}$ can interbreed and produce viable $F_{1}$ and $F_{2}$ progeny. Differences in behaviour or physiology between arrhenotokous and thelytokous strains may reflect long-term effects of a possible Wolbachia infection or of reproductive isolation. We compared the mating ability and the offspring survival of TD and $\mathrm{AD}$ in $P$. herreni and $P$. manihoti, the known hosts of the strains.

\section{Materials and methods}

\section{Cultures}

Cassava plants (Manihot esculenta Crantz) were reared in a greenhouse from cuttings from Colombia (variety CMC40) at $18-32^{\circ} \mathrm{C}$ and $60-95$ per cent r.h.

Phenacoccus herreni was obtained from the Centro Internacional de Agricultura Tropical (CIAT), Colombia, in 1990 and reared on cassava at $22-30^{\circ} \mathrm{C}$. A thelytokous $A$. diversicornis strain from Colombia (termed TD) was also obtained from CIAT, in 1991. It was reared on cassava containing mainly third and fourth instar $P$. herreni at $24-26^{\circ} \mathrm{C}$ and 55-65 per cent r.h.

Phenacoccus manihoti, obtained from Senegal and Nigeria via the International Institute of Tropical Agriculture (IITA), Benin, in 1985, was reared on cassava at $19-25^{\circ} \mathrm{C}$. An arrhenotokous $A$. diversicornis strain (termed AD) originated from material collected between 1982 and 1986 in south-western Brazil (Löhr et al., 1990) and was reared on cassava plants containing mainly third and fourth instar $P$. manihoti, at $24-30^{\circ} \mathrm{C}$ and $40-80$ per cent r.h.

Experiments were carried out at $25 \pm 0.5^{\circ} \mathrm{C}$ (unless stated otherwise) and 60 per cent r.h.

\section{Check for reproductive mode of cultures}

In order to check if our $\mathrm{AD}$ culture consisted of arrhenotokous females only, 36 virgin $\mathrm{AD}$ females 
were confined with a $P$. manihoti-infested cassava plant. Their offspring should all be male. We obtained 144 males and no female offspring, and concluded that our AD culture was entirely arrhenotokous. A similar test was performed with the TD culture. The $120 \mathrm{TD}$ individuals with which the culture was started and their $F_{1}$ offspring were female and we therefore concluded that the TD culture was entirely thelytokous.

\section{Oviposition and rearing}

Third and early fourth instar mealybugs ( $P$. herreni or $P$. manihoti) were placed on a disc of cassava leaf that was placed in a petri dish upside down. A parasitoid was placed on the patch after the mealybugs had settled. Parasitized mealybugs were carefully removed with a small paint brush and placed on the lower side of the leaf of a cassava plant in small gauze cages. After mummification, mealybugs were taken from the leaf cages and placed individually in glass tubes. Emerged parasitoids were fed honey, either with or without antibiotic. Parasitoid emergence was checked daily and parasitoid survival (i.e. survival from oviposition to emergence) was calculated. Mealybugs that disappeared from the leaf cages and mealybugs that had dried out were not included.

\section{Antibiotic and temperature treatment}

We investigated whether thelytokous females could be cured to produce sons by feeding TD females honey mixed with antibiotics or rearing parasitized mealybugs at high temperature. Cured individuals could be used to determine if TD and AD could be crossed to produce fertile female offspring, which would give a clue as to whether arrhenotokous and thelytokous $A$. diversicornis belong to the same species.

Three antibiotics (tetracycline, rifampicin (rifadin) or sulphadiazine) were mixed with honey in concentrations of 1 per cent $(1 \mathrm{mg}$ antibiotic dissolved in 99 $\mathrm{mg}$ honey) or 5 per cent $(5 \mathrm{mg}$ antibiotic in $95 \mathrm{mg}$ honey). TD mummies were placed individually in glass tubes. Directly after their emergence, these TD females, which form the parental (P) generation, received one type of antibiotic in one concentration during two days. Thereafter, they received pure honey. Freshly emerged $F_{1}$ (first offspring generation), $F_{2}$ and $F_{3}$ females either received honey mixed with antibiotic, or pure honey during their entire life. All females were allowed to oviposit in two mealybugs (always $P$. herreni) per day, starting on day 3 of their lives. All parasitized mealybugs were reared out in leaf cages.

For the temperature treatment, TD mummies were placed individually in glass tubes. Emerged females received honey. They were allowed to oviposit in two $P$. herreni per day, starting on day 3 of their lives. Parasitized mealybugs were reared out at 37 or at $33^{\circ} \mathrm{C}$.

\section{Crosses; mating and insemination}

$\mathrm{AD}$ females that had been isolated as mummies to ensure that they were virgin were allowed to mate with TD males. In order to obtain inseminated females, one female and one male were confined in a glass tube for one or two days. The sex of the offspring allowed us to distinguish between successful and unsuccessful crosses. The presence of female offspring would indicate that the TD sperm was used by the $\mathrm{AD}$ female; $\mathrm{F}_{1}$ females are hybrids. $\mathrm{F}_{1}$ males are not hybrid but $\mathrm{AD}$. Epistatic interactions between genes in the parental strains may be disrupted during meiosis in hybrids, causing them to be sterile. The presence of epistatic interactions between the parental genes was investigated by checking the fertility of virgin hybrid $F_{1}$ females.

A failure to cross may result from a failure to inseminate (premating barrier, no sperm transmission) or from a failure to use the sperm. We dissected the females and recorded the presence or absence of sperm in the spermatheca in order to distinguish between these possibilities.

\section{Results}

\section{Male production}

Treatment with antibiotics TD females that were fed the antibiotics tetracycline and rifampicin produced male offspring within two generations, and one female produced a son in the $F_{1}$ (Table 1 ). Note that the $\mathrm{P}$ females were fed antibiotics for only two days. Thelytokous $A$. diversicomis can thus be cured with antibiotics, leading to the conclusion that the asexuality is caused by microorganisms. $F_{1}$ TD females produced sons without being fed antibiotics themselves; thus, they were (at least partly-some still produced sons and daughters) cured because they laid eggs on which the microorganisms did not act. We cannot exclude the presence of the microorganisms; their numbers were at least lowered. Sulphadiazine did not result in male production in two generations and is therefore considered less suitable for obtaining TD males. There were no major differ- 
Table 1 The effect of anitbiotic and temperature treatment on offspring sex and survival (egg to emergence) of Apoanagyrus diversicornis

\begin{tabular}{|c|c|c|c|c|c|c|c|c|c|}
\hline \multirow[b]{2}{*}{ Treatment } & \multirow[b]{2}{*}{ Generation } & \multicolumn{4}{|c|}{ Mother treated } & \multicolumn{4}{|c|}{ Mother not treated } \\
\hline & & $\begin{array}{l}\text { No. of } \\
\text { mothers }\end{array}$ & $\begin{array}{c}\text { No. of } \\
\text { parasitized } \\
\text { hosts }\end{array}$ & $\begin{array}{l}\text { Per cent } \\
\text { survival } \dagger\end{array}$ & $\begin{array}{c}\text { No. of } 03 / \\
\text { no. of } \\
\text { offspring }\end{array}$ & $\begin{array}{l}\text { No. of } \\
\text { mothers }\end{array}$ & $\begin{array}{c}\text { No. of } \\
\text { parasitized } \\
\text { hosts }\end{array}$ & $\begin{array}{l}\text { Per cent } \\
\text { survival } \dagger\end{array}$ & $\begin{array}{c}\text { No. of } 0^{*} \bar{\alpha} \\
\text { no. of } \\
\text { offspring }\end{array}$ \\
\hline Control & $F_{1}$ & & & & & 40 & 144 & 87.5 & $0 / 126$ \\
\hline \multirow[t]{3}{*}{ T 1 per cent } & $F_{1}$ & 7 & 25 & $60.0^{* *}$ & $1 / 15$ & & & & \\
\hline & $\mathrm{F}_{2}$ & 7 & 46 & $60.9^{* *}$ & $27 / 28$ & 2 & 6 & 100 & $4 / 6$ \\
\hline & $\mathrm{F}_{3}$ & & & & & 1 & 7 & 57.1 & $4 / 4$ \\
\hline \multirow[t]{2}{*}{ T 5 per cent } & $F_{1}$ & 4 & 11 & $54.6^{*}$ & $0 / 6$ & & & & \\
\hline & $\mathrm{F}_{2}$ & 1 & 2 & 50.0 & $1 / 1$ & & & & \\
\hline \multirow[t]{2}{*}{ R 1 per cent } & $F_{1}$ & 7 & 10 & 80.0 & $0 / 8$ & & & & \\
\hline & $\mathrm{F}_{2}$ & 3 & 15 & $53.3^{* *}$ & $8 / 8$ & 1 & 9 & 100 & $9 / 9$ \\
\hline R 5 per cent & $F_{1}$ & 2 & 4 & 50.0 & $0 / 2$ & & & & \\
\hline \multirow[t]{2}{*}{ S 1 per cent } & $F_{1}$ & 4 & 8 & 87.5 & $0 / 7$ & & & & \\
\hline & $\mathrm{F}_{2}$ & 3 & 58 & 86.2 & $0 / 50$ & & & & \\
\hline \multirow[t]{3}{*}{ S 5 per cent } & $\mathrm{F}_{1}$ & 2 & 5 & 80.0 & $0 / 4$ & & & & \\
\hline & $\mathrm{F}_{2}$ & 2 & 40 & 80.0 & $0 / 32$ & & & & \\
\hline & & \multicolumn{4}{|c|}{ Parasitized hosts treated } & \multicolumn{4}{|c|}{ Parasitized hosts not treated } \\
\hline Temp. $37^{\circ} \mathrm{C}$ & $\mathrm{F}_{1}$ & 13 & 21 & $0.0^{* *}$ & - & & & & \\
\hline \multirow[t]{3}{*}{ Temp. $33^{\circ} \mathrm{C}$} & $\mathrm{F}_{1}$ & 5 & 17 & 88.2 & $0 / 15$ & & & & \\
\hline & $\mathrm{F}_{2}$ & 4 & 19 & $57.9^{* *}$ & $9 / 11$ & 3 & 5 & $40.0^{*}$ & $2 / 2$ \\
\hline & $\mathrm{F}_{3}$ & & & & & 1 & 8 & 62.5 & $5 / 5$ \\
\hline
\end{tabular}

All parasitoids were TD and all hosts were Phenacoccus herreni. Except for the controls, untreated wasps had a treated mother.

$\mathrm{T}$, tetracycline; R, rifampicin; S, sulphadiazine; Temp., temperature at which offspring were reared out.

$\dagger$ Tested for difference from the survival of the control $\left(\chi^{2}\right.$-test, $\left.{ }^{*} P \leqslant 0.05, * * P \leqslant 0.005\right)$.

ences between the results obtained with 1 per cent and 5 per cent concentrations of any of the antibiotics (Table 1).

Temperature treatment At $37^{\circ} \mathrm{C}$, not a single parasitoid out of 21 parasitized $P$. herreni survived. This temperature was apparently too high to rear out $A$. diversicornis. We therefore switched to using a temperature of $33^{\circ} \mathrm{C}$. All $\mathrm{F}_{1}$ offspring were female. A proportion of the $F_{2}$ was male, both when reared at high and at normal temperatures, so their mothers were at least partly cured (Table 1 ).

\section{Survival}

We compared egg-to-adult offspring survival after treatment with survival of the controls, i.e. untreated TD. Phenacoccus herreni was the host species in all cases. Different treatments had different effects on offspring survival (Table 1).

(C) The Genetical Society of Great Britain, Heredity, 76, 506-513.
Antibiotics Treatment of mothers with tetracycline resulted in a lower offspring survival, both in 1 per cent and 5 per cent concentrations. The rifampicin 1 per cent treatment lowered the offspring survival only if there were males among those offspring. Sulphadiazine treatment of mothers had no effect on offspring survival and it also did not result in male production.

Temperature A temperature of $37^{\circ} \mathrm{C}$ was lethal to the developing $A$. diversicornis. A temperature of $33^{\circ} \mathrm{C}$ had no effect on survival. Offspring survival was lower when males appeared among them, both when reared at 33 and at $25^{\circ} \mathrm{C}$.

\section{Mating ability}

TD females clearly mated less often than AD females (Table 2). There were no differences in mating ability between $\mathrm{TD}$ and $\mathrm{AD}$ males: males of 
both strains inseminated 100 per cent of the AD females and hardly any of the TD females (Table 2). Treating females or their mothers with antibiotics did not significantly affect their mating ability. A small negative effect of antibiotics cannot be excluded as matings were only obtained with untreated females. The sample size may be too small to ensure sufficient power to detect a possible effect.

Twenty-minute observations of $A$. diversicornis pairs directly after placing them together showed that males of both strains were active in courting all females. TD and AD males tried to approach TD

Table 2 The proportion of female Apoanagyrus diversicornis that was inseminated after having been confined with a male for 1 or 2 days (number of pairs tested is indicated in parentheses)

\begin{tabular}{|c|c|c|}
\hline q & $\mathrm{AD}$ & oTD \\
\hline $\mathrm{AD}$ untreated & $1.00^{\mathrm{aA}}(18)$ & $1.00^{\mathrm{aC}}(8)$ \\
\hline $\begin{array}{l}\text { TD overall } \\
\text { untreated } \\
\text { treated }\end{array}$ & $\begin{array}{l}0.06^{\mathrm{bB}}(32) \\
0.10(20) \\
0.00(12)\end{array}$ & $\begin{array}{l}0.00^{\mathrm{bD}}(13) \\
0.00(5) \\
0.00(8)\end{array}$ \\
\hline ATD untreated & & $0.33^{\mathrm{CD}}(3)$ \\
\hline
\end{tabular}

Entries with the same letter are not significantly different from each other [Fisher's exact probability test, two-sided, $\alpha=0.05$; small letters for tests between males (tested within rows only), capitals for tests between females (tested within columns only)]. As data are used more than once, the test statistics are dependent on each other. Hence, $P$-values have to be combined and dependencies must be taken into account. Therefore the improved Bonferroni method was applied. This method, which is explained in detail in Haccou \& Meelis (1992, p. 248) and based on the original papers by Simes (1986) and Hochberg (1988), ensures that the overall $\alpha$ is at most 5 per cent. Treated: with antibiotics. females as they did with AD females. TD females, however, often moved away from the male, whereas AD females allowed males to approach them. Within the observation period mating with an $\mathrm{AD}$ female was observed on several occasions, whereas no TD females were observed to mate.

\section{Crosses}

Seven of the $11 \mathrm{AD}$ females that were inseminated by TD males (Table 3 ) produced daughters. Female offspring result from fertilized eggs and thus the $F_{1}$ females were a cross between the two strains. These hybrids will be denoted by ATD. The males in the $F_{1}$ resulted from unfertilized eggs of the $A D$ females so they were AD. The survival from egg to adult of AD males in $P$. manihoti and $P$. herreni is known from separate experiments (Table 4), and allowed us to deduce the number of male and female eggs laid (i.e. the primary sex ratio). We calculated the survival probability of ATD $F_{1}$ females on the basis of the deduced primary sex ratio and the result is given in Table 4.

Three $F_{1}$ females were allowed to oviposit and so produce $\mathrm{F}_{2}$ offspring (Table 3 ). The $\mathrm{F}_{2}$ males resulted from unfertilized eggs of the ATD females and they were therefore ATD. The last line in Table 3 enabled the calculation of male ATD offspring survival in $P$. manihoti and $P$. herreni. ATD survival from egg to adult turned out to be equal for males and females (Table 4).

The $F_{1}$ hybrids were found to be fully fertile. The survival of hybrid $F_{2}$ was equal to the survival of hybrid $\mathrm{F}_{1}$ individuals. This was true for hybrids reared from both mealybug species (Table 4). Moreover, $\mathrm{F}_{2}$ hybrid survival in $P$. herreni was as high as the survival of both parental strains in this mealybug, although sample sizes are small. There were no indications of $F_{2}$ hybrid breakdown. It is concluded

Table 3 The result of crosses between Apoanagyrus diversicornis strains

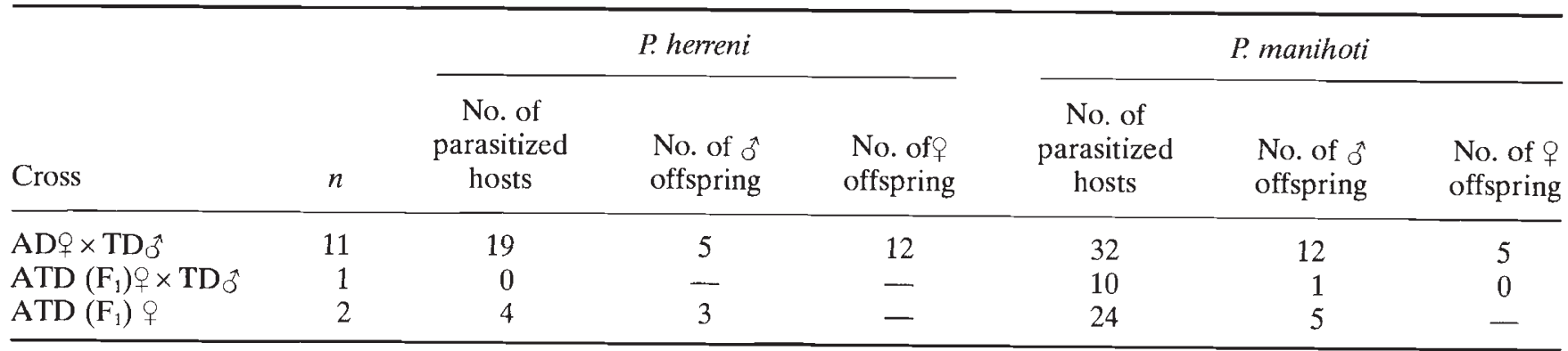

Insemination was confirmed by dissection of the females after oviposition. Because of a shortage of Phenacoccus herreni in the culture, $P$. manihoti was also used as a host. Survival of TD and ATD in this host species is, however, lower than in $P$. herreni (see Table 4). $n$, no. of female parasitoids. 
that $\mathrm{AD}$ and $\mathrm{TD} A$. diversicornis can be crossed to produce viable $F_{1}$ and $F_{2}$ offspring.

ATD survival in $P$. manihoti was about two-thirds less than in $P$. herreni, and intermediate between the survival of the parental strains (Table 4). ATD individuals inherited the low survival probability in $P$. manihoti from the TD parent: TD have a survival of only 0.045 in $P$. manihoti (Table 4). The $\mathrm{F}_{2}$ survival of the hybrids might seem to be exceptionally low (Table 3), but this is caused by rearing them out in $P$. manihoti and it is not an indication of $\mathrm{F}_{2}$ hybrid breakdown, as shown by high survival in $P$. herreni.

\section{Discussion}

Male production was induced by feeding thelytokous females the antibiotics tetracycline or rifampicin, and by rearing parasitized mealybugs at $33^{\circ} \mathrm{C}$. This shows that asexuality in $A$. diversicornis was caused by microorganisms. PCR amplification of $16 \mathrm{~S}$ ribosomal DNA from TD females (J.H. Werren, unpublished results) showed that the microorganism with which these are infected is, as was expected, a member of the genus Wolbachia. No Wolbachia ribosomal DNA could be found in AD females. This indicates that the arrhenotokous strain of $A$. diversicornis is indeed free of Wolbachia.

Crosses between male $A$. diversicornis from Colombia (TD) and female $A$. diversicornis from south-western Brazil (AD) were fully compatible. This suggests that, on an evolutionary time scale, the separation of $\mathrm{AD}$ and TD has occurred recently.

Stouthamer \& Kazmer (1994) showed that Wolba-

Table 4 Survival of AD, TD and hybrid Apoanagyrus diversicornis in the hosts Phenacoccus herreni and $P$. manihoti

\begin{tabular}{|c|c|c|c|}
\hline & $\mathrm{AD}$ & TD & ATD \\
\hline P. manihoti & 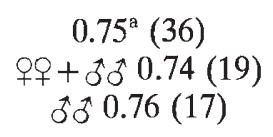 & $0.045^{b}(44)$ & $\begin{array}{c}0.25^{c}(40) \\
\text { 우 } 0.31(16) \\
\text { sô } 0.21(24)\end{array}$ \\
\hline P. herreni & $0.81^{\mathrm{a}}(127)$ & $0.88^{\mathrm{a}}(144)$ & $\begin{array}{c}0.88^{\mathrm{a}}(17) \\
\text { 오 } 0.92(13) \\
\text { ơ } 0.75(4)\end{array}$ \\
\hline
\end{tabular}

Sample sizes are indicated in parentheses.

Entries with the same letter are not significantly different $\left(\alpha=0.05, \chi^{2}\right.$-test and Student's $t$-test).

The improved Bonferroni method (Haccou \& Meelis, 1992) was applied.

Male and female survival were compared with each other for AD in P. manihoti and for ATD in both mealybug species; no differences were found $(\alpha=0.05)$. chia act by preventing segregation of chromosomes during the first mitotic division (which takes place after oviposition). Antibiotics ingested by the $A$. diversicornis female or heat treatment of the eggs she laid did not have an effect on the sex of those eggs. Apparently, Wolbachia action on the $F_{1}$ eggs could not be prevented any more. This is analogous to the results of, for example, Gordh \& Lacey (1976) and Laraichi (1978) found after heat treatment. Antibiotics administered to parental generation $A$. diversicornis reduced the numbers of Wolbachia in the $F_{1}$, because the $F_{2}$ also contained males, even if the $\mathrm{F}_{1}$ were not treated. Apoanagyrus are synovigenic (i.e. they mature their eggs during their lives), but they carry some ripe eggs at eclosure. TD females might have produced a larger proportion of males in the $F_{1}$ if the antibiotics had been administered during their entire life instead of during two days only, or if the females had lived and oviposited longer. Antibiotics then might have prevented Wolbachia action on newly ripened eggs. The only $F_{1}$ male that appeared was laid by its mother on day 6 of her life, suggesting that it may have resulted from an egg that the mother ripened after she emerged. Females that were administered antibiotics usually did not live longer than 6 days.

Treatment with sulphadiazine during two generations did not lead to male production. The parasitoids given this treatment lived longer than parasitoids kept without food (pers. obs.), suggesting that the treated wasps have eaten the honey-sulphadiazine solution. The antibiotic may not have reached the microorganisms, have been ineffective, or taken more time to become effective. The longevity and fecundity of Trichogramma pretiosum were significantly lowered by tetracycline, but not by rifampicin or sulphamethoxazole (Stouthamer, 1990). Tetracycline also had the largest effect on $A$. diversicornis. It lowered the offspring survival from egg to adult. There was no effect of sulphamethoxazole. We found some mortality associated with the production of males by treated and untreated $F_{1}$ mothers in the rifampicin and temperature treatment. Wolbachia restore diploidy by gamete duplication, resulting in completely homozygous offspring (Stouthamer \& Kazmer, 1994). Thus, deleterious mutations generally are expressed in Wolbachiainfected females. Deleterious mutations in genes encoding characters that are expressed in males only, however, are silent in females. Such mutations may be the cause of the mortality that was associated with male production.

Male behaviour and function were apparently normal in sons from cured thelytokous females. 
Insemination by TD males occurred as frequently as insemination by $\mathrm{AD}$ males. The female sexual behaviour, however, was clearly affected: both asexual and cured TD females were much less often inseminated than $\mathrm{AD}$ females. A similar result was obtained by Rössler \& DeBach $(1972,1973)$ for the aphelinid Aphytis mytilaspidis and by Stouthamer et al. (1990b) for strains of Trichogramma pretiosum. Carson et al. (1982) found a rapid decay of female sexual behaviour in a parthenogenetic strain of Drosophila mercatorum. Our data suggest an interesting difference between genes coding for male and female sexual behaviour, in the speed with which deleterious mutations accumulate in thelytokous females. Being not expressed in TD, the male sexual behaviour is expected to degenerate as a neutral character, whereas female sexual behaviour is expressed and may be selected against if there is a cost of maintaining sexual behaviour in thelytokous females. This difference between female traits (expressed and possibly selected against) and male traits (not expressed in asexuals) may lead to a higher rate of decay of female than of male sexual behaviour in an asexual population. This may explain the results of Carson et al. (1982).

Attempts to establish a sexually reproducing $A$. diversicornis strain from entirely thelytokous material failed because we could not obtain matings between asexual or cured TD females and TD males. This is analogous to the result of Zchori-Fein et al. (1992): 'cured' males of Encarsia formosa failed to inseminate asexual or cured conspecific females. An entirely sexually reproducing TD line would have made it possible to investigate whether the sex allocation behaviour of a strain had changed after a period of asexuality, by comparing it with the sex allocation of the $\mathrm{AD}$ strain. $\mathrm{AD}$ males occasionally inseminated TD females, but no genetic markers were available in $A$. diversicornis to investigate whether inseminated TD females use the sperm of AD males. The mating frequency of the ATD females appeared to be intermediate between that of the parental strains.

At least seven of the $11 \mathrm{AD}$ females that were inseminated by TD males successfully used the sperm. The other four females may have laid female eggs as well, but the low survival of the ATD hybrids in $P$. manihoti caused the majority of the offspring to die. The hybrids only survived well in $P$. herreni. (At the time of the crossing experiments, there was a shortage of $P$. herreni in the culture, hence the extensive use of $P$. manihoti as a host.) Our results show that in $A$. diversicornis, offspring survival probability is not a maternally inherited factor but (like mating frequency) appears to be intermediate between the survival probability of the maternal and paternal strain.

TD occur on $P$. herreni in Colombia, and AD have been found on $P$. manihoti in central South America. The low survival of TD in $P$. manihoti may be because of the absence of this host species from the parasitoid's native area (Commonwealth Institute of Biological Control, unpublished data). AD survive well in $P$. manihoti and in $P$. herreni and both host species occur in central South America (Yaseen, 1981; Löhr et al., 1990). Gene flow between AD and TD is unlikely because, as far as we know, the populations are geographically isolated. If parasitoids were to migrate, gene flow from $A D$ to TD would still be unlikely because TD females are rarely inseminated by $\mathrm{AD}$ males. TD males may occasionally occur because of high temperatures. If TD individuals migrated to central South America, genetic material of the two strains may be mixed because TD males cross with $\mathrm{AD}$ females. It is very unlikely that this would lead to the Wolbachia infection being transferred to $\mathrm{AD}$ females as sperm usually do not carry Wolbachia. Horizontal transmission of Wolbachia via the host (i.e. by superparasitism) may be possible. The lack of congruence between the phylogeny of Wolbachia and their insect hosts suggests that horizontal transfer of Wolbachia has occurred frequently (O'Neill et al., 1992; Rousset et al., 1992; Werren et al., 1995).

\section{Acknowledgements}

We would like to thank CIAT, Colombia, for providing cassava cuttings, the Botanical Garden of Leiden University for rearing the cassava plants, R. Stouthamer and M. Antolin for discussion, C.D. Hofker for assistance with the cultures and additional data, J.H. Werren for the molecular analysis, and R. Stouthamer, J.H. Werren and two anonymous referees for comments on the manuscript. Part of this research was financed by the Netherlands Ministry for Development Cooperation.

\section{References}

BREEUWER, J. A. J., STOUTHAMER, R., BARNS, S. M., PELletIER, D. A., WEISBURG, W. G. AND WERREN, J. H. 1992. Phylogeny of cytoplasmic incompatibility micro-organisms in the parasitoid wasp genus Nasonia (Hymenoptera: Pteromalidae) based on $16 \mathrm{~S}$ ribosomal DNA sequences. Insect Mol. Biol., 1, 25-36.

CARSON, H. L., CHANG, L. S. AND LYTTLE, T, R. 1982. Decay of female sexual behavior under parthenogenesis. Science, 218, 68-70. 
GORDH, G. AND LACEY, L. 1976. Biological studies of Plagiomerus diaspidis Crawford, a primary internal parasite of diaspidid scale insects (Hymenoptera: Encyrtidae; Homoptera: Diaspididae). Proc. Entomol. Soc. Washington, 78, 132-144.

Haccou, P. AND MEelis, E. 1992. Statistical Analysis of Behavioural Data. Oxford University Press, Oxford.

HERREN, H. R. AND NEUENSChWANDER, P. 1991. Biological control of cassava pests in Africa. Ann. Rev. Ent., 36, 257-283.

HOCHBERG, Y. 1988. A sharper Bonferroni procedure for multiple tests of significance. Biometrika, 75, 800-802.

LARAICHI, M. 1978. L'effet de hautes temperatures sur le taux sexuel de Ooencyrtus fecundus Hymenoptera: Encyrtidae. Entomologia. exp. appl., 23, 237-242.

LÖHR, B., VARELA, A. M. AND SANTOS, B. 1990. Exploration for natural enemies of the cassava mealybug, Phenacoccus manihoti (Homoptera: Pseudococcidae), in South America for the biological control of this introduced pest in Africa. Bull ent. Res., 80, 417-425.

NOYEs, J. S. AND HAyAT, M. 1994. Oriental Mealybug Parasitoids of the Anagyrini (Hymenoptera: Encyrtidae). CAB International, Wallingford, UK.

o'NEILl, S. L., GIORDANO, R., COLBERT, A. M. E., KARR, T. L. AND ROBERTSON, H. M. 1992. 16S rRNA phylogenetic analysis of the bacterial endosymbionts associated with cytoplasmic incompatibility in insects. Proc. Natl. Acad. Sci. U.S.A., 89, 2699-2702.

PIJLS, J. W. A. M. AND ALPHEN, J. J. M. VAN 1996. On the coexistence of the cassava mealybug parasitoids Apoanagyrus diversicornis and A. lopezi (Hymenoptera: Encyrtidae) in their native South America. Bull. ent. Res., 86, (in press).

RÖSSLER, Y. AND DEBACH, P. 1972. The biosystematic relations between a thelytokous and an arrhenotokous form of Aphytis mytilaspidis (Le Baron) (Hymenoptera: Aphelinidae). I. The reproductive relations. Entomophaga, 17, 391-423.

RÖSSLER, Y. AND DEBACH, P. 1973. Genetic variability in a thelytokous form of Aphytis mytilaspidis (Le Baron) (Hymenoptera: Aphelinidae). Hilgardia, 42, 149-175.
Rousset, F., Bouchon, D., Pintureau, B., JUChault, P. AND SOlignaC, M. 1992. Wolbachia endosymbionts responsible for various alterations of sexuality in arthropods. Proc. R. Soc. B, 250, 91-98.

SIMES, R. J. 1986. An improved Bonferroni procedure for multiple tests of significance. Biometrika, 73, 751-754.

STOUTHAMER, R. 1990. Effectiveness of several antibiotics in reverting thelytoky to arrhenotoky in Trichogramma spp. Les Colloques de l'INRA, 56, 119-122.

STOUTHAMER, R. AND KAZMER, D. J. 1994. Cytogenetics of microbe-associated parthenogenesis and its consequences for gene flow in Trichogramma wasps. Heredity, 73, 317-327.

STOUTHAMER, R., LUCK, R. F. AND HAMILTON, w. D. 1990a. Antibiotics cause parthenogenetic Trichogramma (Hymenoptera / Trichogrammatidae) to revert to sex. Proc. Natl. Acad. Sci. U.S.A., 87, 2424-2427.

STOUTHAMER, R., PINTO, J. D., PlatNer, G. R. AND LUCK, R. F. 1990b. Taxonomic status of thelytokous forms of Trichogramma (Hymenoptera: Trichogrammatidae). Ann. Entomol. Soc. Am., 83, 475-481.

STOUTHAMER, R., BREEUWER, J. A. J., LUCK, R. F. AND WERREN, J.H. 1993. Molecular identification of microorganisms associated with parthenogenesis. Nature, 361, $66-68$.

VAN DRIESCHE, R. G., BELlotTI, A., HERRERA, C. J. AND CASTILlo, J. A. 1987. Host preferences of two encyrtid parasitoids for the Columbian Phenacoccus spp. of cassava mealybugs. Entomologia. exp. appl., 43, 261-266.

WERREN, J. H., ZHANG, W. AND GUO, L. R. 1995. Evolution and phylogeny of Wolbachia: reproductive parasites of arthropods. Proc. R. Soc. B, 261, 55-71.

YASEEN, M. 1981. Report on surveys for cassava mealybugs (Phenacoccus spp.) and their natural enemies in South America (January-March 1981). Unpublished Report of the Commonwealth Institute of Biological Control, $7 \mathrm{pp}$.

ZCHORI-FEIN, E., ROUSH, R. T. AND HUNTER, M. S. 1992. Male production induced by antibiotic treatment in Encarsia formosa (Hymenoptera: Aphelinidae), an asexual species. Experientia, 48, 102-105. 